\title{
THE ELECTRICAL RESEARCH ASSOCIATION
}

$\mathrm{T}$ HE forty-fourth annual general meeting of the Electrical Research Association held on April 28 received the annual report for 1964 *.

In a foreword, Sir Ronald German, president of the Association, refers to the work of the Association having been established, in the main, in relation to the electricity supply industry, but in recent years increasing attention had been directed to light current problems and this trend would almost certainly be accentuated.

General observations on the year's work are made in a short introductory section constituting the report of the Council. This is followed by the Director's report on researches, which summarizes the activities of the six research divisions and the Electronics Department. A short section is devoted to membership, public relations, information bureau and library. A full list is given of the research reports issued during the year. The remainder of the report comprises a list of members of the Association, together with members of the Council and committees. The committees are listed under the particular division to which each is attached, and of particular value is the inclusion of a statement of the terms of reference of each committee.

The terms of Government grant to the Association, made through the Department of Scientific and Industrial Research, came to an end in December 1964, and during the year a new application had been prepared and submitted. The result of this application had been the offer of a 28 per cent grant for a three-year period, subject to the Association collecting at least $£ 350,000$ of grantearning income.

Since 1955 the income of the Electrical Research Association has increased by 90 per cent, or, more realistically, in terms of 1955 spending power, by 52 per cent, to its present annual total of some $\$ 652,000$. It is, however, particularly noteworthy that during this period the proportion of total income derived from sponsored and specially supported researches has increased from 20 to 41 per cent.

At the end of the year, the Association transferred to the University of Reading the Field Station at Shinfield, where for the past twenty years work has been carried on relating to the applications of electricity in agriculture and horticulture. It was felt that there would be advantages in co-ordinating more closely the work at the Shinfield Station with that of the Faculty of Agriculture of the University and to that end a joint agreement was drawn up by the University, the Electricity Council and the Electrical Research Association.

When the Association moved its headquarters and main laboratories to Leatherhead in 1956, the facilities for switchgear testing remained for the time being at Perivale. During 1963-64 a new switchgear laboratory was built and equipped at Leatherhead and the work transferred. The formal opening of this new laboratory was in October 1964.

In the Division dealing with insulating materials, results are reported in two programmes of fundamental investigation. In relation to the stable state, work on the dielectric effects of hydrogen bonding has been completed and a paper prepared dealing with possible implications for biological structures. An important fact has emerged concerning the mechanism of degradation of ceramics under an electric field at high temperatures, namely, that it is electro-chemical rather than purely electrical in character and is very dependent on the materials of the electrodes and on the ambient atmosphere. Further * The Electrical Research Association. Forty-fourth Annual Report for
the year ended December 31, 1964. Pp. 85. (Leatherhead: The Electrical Research Association, 1965.) investigations have been made on the trapping of surface charges in dielectrics and an apparatus has been constructed which enables charges to be deposited, either directly electrically or as a result of photo-electric emission. Theoretical work on dielectric properties has led. to a generalization of the Onsager theory to the frequencydependent case, and it has been shown that electrostatic dipole coupling plays an important part in determining the distribution of relaxation times. Research on fundamental phenomena of instability has included the development of a theory of ionic diffusion in impregnated paper capacitors and this has been found to be in satisfactory agreement with observation. Another theoretical study deals with the propagation of breakdown channels through liquids and regards the channel as a vapour bubble at high pressure. The subject of the intrinsic electric strength of plastics is being re-examined using an improved technique of measurement. By the new method, intrinsic electric strengths of about twice the value given by the old method have been obtained at a temperature of $85^{\circ} \mathrm{C}$.

In the Power Plant Division work on steels for high temperature and on the properties of steam continues. The investigation of the magnetically constricted lowpressure d.c. arc has been completed. This study has provided useful information on the effects of boundary layers at electrodes immersed in a low-pressure laminar stream of plasma.

A special Research Advisory Committee and Technical Panel is directing the work on the synthetic testing of cireuit breakers which comes within the Division of Switchgear, Transformers and Power System Behaviour. This represents a major co-operative undertaking in which manufacturers, the Central Electricity Generating Board and the Association are involved. It is hoped that the work will lead to the national adoption of a standard method of synthetic circuit-breaker testing. Work in progress to establish the validity of the method as applied to air-blast circuit breakers has compared the severity of the direct and the synthetic test in several hundred trials made at three of the major stations of the Association of Short-circuit Testing Authorities. The maximum power-level of these tests has been 1,200 MVamp and the maximum current $40 \mathrm{k} . \mathrm{amp}$.

Work continues at the British Iron and Steel Research Association Laboratories on improved alloys for transformer sheet. The demonstration of a relationship between resistivity and saturation has prompted a design study among manufacturers to determine whether any reduction in saturation could be accepted in return for reduced losses from increased resistivity.

In relation to switching over-voltages, useful information on the detail of surge generation and transfer has been obtained from the analysis of data from site tests on a 100-MV generator/transformer installation. Energizing a $132 / 33-\mathrm{kV}$ transformer, to which a $33-\mathrm{kV}$ earthing transformer was connected, demonstrated magnification of the switching surges transferred to the earthing transformer resulting from resonances between the $132 \mathrm{kV}$ and the $33-\mathrm{kV}$ systems. An investigation in progress on tolerable levels of discharge severity for oil-impregnated, paper-insulated bushings has demonstrated that degradation can be caused by test over-voltages and by surges such as may occur in service.

In the field of power system analysis, the increased facilities of the network analyser or, as it is termed, "the Integrated Computer" have been used to study transient problems of greater complexity. In addition, feasibility studies have been made of the desirability of coupling a small digital computer to the transient analyser and of 
the potentialities of such a hybrid system in power system applications.

Experimental work on the current-carrying capacity of cables continues in relation both to steady-state and to fault conditions, and considerable information has been obtained from the co-operative field investigation on the influences of the thermal properties of soil. In relation to the calculation of cable ratings, methods are being developed for the utilization of digital computer programmes.

The behaviour of the British electricity supply system in relation to thunderstorm activity throughout the ten-year period 1950-60 is the subject of a comprehensive report. The report examines the frequency of supply interruptions in the high-voltage system, their relationship with thunderstorm activity, the effect of arc suppression coils, the rate of equipment failure and the protective effects of surge diverters and spark gaps on the rate of transformer failures. Reports have also been issued analysing the frequency and distribution of thunderstorms in Britain for the years 1962 and 1963 , and a ten-year thunderstorm map of Britain for the period 1955-64 is in preparation. The collection of statistical information on the frequency of lighting discharges in different parts of the world is being facilitated by the adoption, as an interim international standard, of a modification of a form of lightningflash counter originally developed in association with the Electrical Research Association.

Electric heating is represented, in the main, by a group of researches relating to off-peak floor heating, to ceiling heating and to thermal storage. The storage of off-peak energy by means of the lime-water reaction has been studied on a full-scale test equipment in the laboratory and, following a comprehensive theoretical assessment, experiments have been put in hand on the use of sodium hydroxide.

Within the division dealing with industrial applications, the programme of work on electrical equipment for hazardous atmospheres continues. In the same division research on methods of reducing contact erosion is being pursued by a detailed study of a novel dissimilar metal system.
It appears, from theoretical considerations, that metal transfer could be virtually eliminated for a certain range of circuit conditions by the use of suitably chosen dissimilar contact metals. This has been confirmed in a series of experiments using platinum as the positive and silver or palladium as the negative electrode. Experimental work on unbalanced magnetic pull in electrical machines is now in progress on a machine specially constructed and instrumented for these measurements.

The major part of the programme of the Electronics Department is on thin films and is supported by a group of industrial contributors and by the Ministry of Aviation. It is reported that work on the deposition of metal from an ion beam has encountered difficulties, due to a flow of neutral gas molecules from the ionization chamber through the extractor electrode. The Penning ion source has been replaced by one utilizing electron bombardment to ionize copper vapour. Experimental capacitors have been made by depositing silicon oxide dielectric films on gold electrodes. Early results, however, suggest that the silicon oxide films deposited under ultra-high vacuum conditions may be insufficiently oxidized. Work on the conduction mechanism in thin films has led to an investigation of the influence of the substrate material. It has been shown that the electrical conductivity of glasses used as substrates for microcircuits is high enough to contribute to the transport of electric charges by a thin film deposited on the surface. Two new lines of investigation have been started, one on the properties of semi-conductor materials in thin film form and the other on the resistance changes occurring in thin gold films when subjected to mechanical strain.

Some of the fundamental theoretical work which has been done in applying the theory of the electrical discharge to certain astrophysical phenomena has undergone further comparison with observation. During the past year it has been demonstrated that the maximum magnetic fields recorded by Babcock's solar magnetograph of the order of 1,000 gauss are compatible with the much larger fields of $10^{4}-10^{5}$ gauss deduced from the theory of solar flares some years ago.

J. Greig

\section{POWER SUPPLY IN BRITAIN}

$I^{\mathrm{N}}$ $\mathrm{N}$ asking the House of Commons on August 4 to note the Report and Accounts of the Electricity Council for 1963-64 and of the Central Electricity Generating Board for 1963-64, Mr. F. Le日, the Minister of Power, said that the average cost of new conventional power stations had fallen from about $£ 60$ per $\mathrm{kW}$ in 1955 to about $£ 40$ to-day. Britain had by far the largest output from commercial nuclear power stations of any country, and was producing more nuclear power than the whole of the rest of the Western world, including the United States. Whatever the outcome of the Government's present review of the second nuclear power programme, the industry would continue to need coal for many years to come, and the Generating Board was now using 64 million tons of coal, compared with 61 million tons in 1963-64. Fifteen new coal-fired stations were under construction, partly to replace the older stations which were closing down, and on completion of these stations the Generating Board would have much of its capacity in the form of new coal-fired stations. The working life of the new stations would be twenty-five years or more, and they would burn coal with high efficiency in the 500-MW sets which had been adopted as standard for the next few years. Forty-seven of these sets were now on order and they would produce substantially more power than the entire capacity of the industry ten years ago.

On the transmission side, the industry was introducing transmission at $400 \mathrm{kV}$. Great efforts were being made at considerable cost to reduce the impact of the new lines on the countryside and this research had high priority. Some research was being undertaken into the use of d.c. transmission instead of a.c., and about one-third of the total expenditure of the Board on transmission lines in 1964 was spent on underground cables. This was expected to rise to more than two-thirds by 1970 , and during the three years, commencing in 1968, the Board expected to spend $£ 39$ million on 1,350 miles of overhead lines, and $£ 107$ million on 500 miles of underground cable. Rural electrification was now approaching completion, and 94 per cent of the 280,000 farms in England and Wales had an electricity supply. In distribution, as in generation and transmission, research was going ahead and a new laboratory had been set up at Capenhurst. The major effort at the now laboratory would be concentrated on research into distribution and on appliances and methods of using electricity as part of a research programme covering generation, transmission and distribution, on which the industry planned to spend $£ 10$ million this year.

The Minister's observations on research were generally welcomed in the debate, but Mr. A. F. Palmer suggested that there might have been some neglect of research into the use of direct current. Sir Richard Nugent pointed out that the Select Committee on the Nationalized Industries had been critical of expenditure on research on transmission, and especially on distribution, particularly 